\title{
LETRAMENTO: PROCESSOS EDUCACIONAIS NO CONTEXTO SOCIAL E POLÍTICO
}

\author{
APRENDIZAJE DE LECTOESCRITURA “LETRAMENTO": PROCESOS \\ EDUCATIVOS EN CONTEXTO SOCIAL Y POLÍTICO
}

\section{LITERACY: EDUCATIONAL PROCESS IN SOCIAL AND POLITICAL CONTEXT}

\author{
Marcos Antônio Batista da SILVA ${ }^{1}$ \\ Cleomar AZEVEDO ${ }^{2}$
}

RESUMO: O presente artigo apresenta reflexões sobre uma pesquisa em desenvolvimento que propõe analisar discursos referentes a letramento. A pesquisa considera as produções elaboradas no período compreendido entre 1995 e 2015 . O estudo está sendo feito por meio de uma consulta sistemática buscando identificar e catalogar artigos sobre essa temática em periódicos indexados do país. O exercício de recuperação analítica da produção sobre letramento no Brasil tem um início que o demarca e que prossegue de maneira ampliada com esta pesquisa. Como tais publicações situam o conceito de letramento? Que configurações sobre as desigualdades de gênero, étnico-raciais e idade são possíveis de se apreender em publicações sobre letramento? Quais temas, áreas do conhecimento e nível de ensino têm ocupado com maior frequência essas publicações? Teoricamente está pesquisa será referenciada por autores que dão ênfase à necessidade de se considerar o ambiente social em que o sujeito está interagindo, isto é, suas práticas de leitura e escrita, voltadas às necessidades de uso social (SOARES, 2001; KLEIMAN, 1995; AZEVEDO, 2007). A perspectiva da pesquisa é adotar como método a hermenêutica de profundidade (HP) - proposta de Thompson (2011), bem como dos aportes metodológicos de Bardin (2011).

PALAVRAS-CHAVE: Letramento. Periódicos. Desigualdades. Psicologia educacional.

RESUMEN: Este artículo presenta reflexiones sobre la investigación en el desarrollo que tiene como objetivo analizar los discursos relacionados con aprendizaje de lectoescritura .La investigación considera las producciones desarrolladas en el período entre 1995 y 2015. El estudio se realiza a través de una consulta sistemática buscando identificar y artículos del catálogo también sobre este tema en revistas indexadas en el país. La recuperación analítica ejercicio de la producción en aprendizaje de lectoescritura en Brasil tiene un principio que demarca, y los beneficios se expandió manera con esta investigación. Como este tipo de publicaciones sitúan el concepto de

${ }^{1}$ Universidade de Coimbra- Centro de Estudos Sociais(CES). Coimbra - Portugal. Pós-doutorando no Centro de Estudos Sociais (CES) da Universidade de Coimbra, Portugal. E-mail: marcos.psico@yahoo.com.br.

${ }^{2}$ Centro Universitário FIEO (UNIFIEO), Osasco - SP - Brasil. Professora e pesquisadora do Programa de Psicologia Educacional. E-mail: cleomar.azevedo@uol.com.br.

RIAEE - Revista Ibero-Americana de Estudos em Educação, Araraquara, v.12, n.4, p. 2138-2154, out./dez. 2017. 
aprendizaje de lectoescritura? ¿Qué ajustes en las desigualdades de género, étnicoracial y la edad son posibles de captar en las publicaciones sobre aprendizaje de lectoescritura? ¿Qué temas, áreas de conocimiento y nivel de educación son más a menudo ocupados estas publicaciones? Teóricamente esta investigación se hace referencia por autores hacen hincapié en la necesidad de considerar el entorno social en el que el sujeto está interactuando, es decir, sus prácticas de lectura y escritura, dirigidos a las necesidades de uso social (SOARES, 2001; KLEIMAN, 1995; AZEVEDO, 2007). El punto de vista de la investigación consiste en adoptar como método la profundidad de la hermenéutica (HP) - propuesta de Thompson (2011), así como las aportaciones metodológicas de Bardin (2011).

PALAVRAS CLAVE: La instrucción. Revistas. Las desigualdades. Psicología de la educación.

ABSTRACT: This article presents thoughts on developing research do you propose to analyze speeches relating to literacy. The research considers the elaborate productions in the period between 1995 and 2015. The study is being done by means of a systematic consultation seeking to identify and tag articles on this subject in indexed journals in the country. The analytical recovery of production exercise on literacy in Brazil has a beginning that demarcates and continues in a way extended with this research. As such publications are the concept of literacy? What settings on gender inequalities, racialethnic and age are possible to grasp in publications on literacy? Which themes, areas of knowledge and level of education have occupied more frequently these publications? Theoretically is research being referenced by authors who give emphasis to the need to consider the social environment in which the subject is interacting, i.e. their practices of reading and writing, geared to the needs of social use (SOARES, 2001; KLEIMAN, 1995; AZEVEDO, 2007). The research perspective is to adopt as method hermeneutics (HP) - proposal for Thompson (2011), as well as the methodological contributions of Bardin (2011).

KEYWORDS: Literacy. Periodicals. Inequalities. Educational Psychology.

\section{Introdução}

Esta pesquisa propõe analisar discursos sobre letramento publicados no Brasil de 1995 a 2015. A partir da revisão da literatura poderemos ter ideia do que já foi e do que ainda necessita ser pesquisado. A investigação se insere na linha de pesquisa "Processos educacionais no contexto social e político" do Programa de Psicologia Educacional do Centro Universitário FIEO. Esta linha de pesquisa desenvolve estudos que consideram as teorias de aprendizagem e seus aspectos culturais, sociais e psicológicos. Isto é, aborda os processos de escolarização e o desenvolvimento de componentes simbólicos e linguísticos nos relacionamentos interativos, sociais e políticos. 
O exercício de recuperação analítica da produção sobre letramento no Brasil tem um início que o demarca e que prossegue de maneira ampliada com esta pesquisa. Assim, para compreendermos o conceito de letramento, torna-se importante que façamos uma retrospectiva do uso do termo no Brasil. O termo letramento foi introduzido no país através da literatura de Mary Kato nos meados da década de 1980. Uma das primeiras ocorrências está no livro "No mundo da escrita: uma perspectiva psicolinguística". Anos mais tarde, em "Adultos não alfabetizados: o avesso do avesso", Tfouni (1986), em sua tese de doutorado, distinguiu alfabetização de letramento: enquanto a alfabetização se ocupa da aquisição da escrita por uma pessoa, ou um grupo de pessoas, o letramento da ênfase aos aspectos sócio-historicos da aquisição de um sistema escrito por uma sociedade.

Para Soares (2001), talvez seja esse o momento em que letramento ganha estatuto de termo técnico no léxico dos campos da Educação e das Ciências Linguísticas. "Letramento é a palavra recém-chegada ao vocabulário da Educação e das Ciências Linguísticas: é a na segunda metade dos anos 80, [...] que surge no discurso dos especialistas dessas áreas" (SOARES, 2001, p.15). Desde então, a palavra torna-se cada vez mais frequente no discurso escrito e falado por especialistas, particularmente pelo lançamento do livro de "Os significados do letramento: uma nova perspectiva sobre prática social da escrita", de Kleiman (1995).

Segundo Kleiman (1995), por um lado, o conceito de letramento começou a ser introduzido nos meios acadêmicos como tentativa de separar os estudos sobre o impacto social da escrita dos estudos sobre a alfabetização, cujas conotações escolares destacam as competências individuais no uso e na prática da escrita. Para a autora eximem-se dessas conotações os sentidos que estudiosos como Freire (1980) atribuíram à alfabetização, isto é, que a vê como capaz de levar a pessoa analfabeta a organizar reflexivamente seu pensamento, desenvolver a consciência crítica e introduzi-la num processo real de democratização da cultura e de libertação. Por outro lado, os estudos sobre letramento examinaram o desenvolvimento social que acompanhou a expansão dos usos da escrita desde o século XVI, tais como as mudanças políticas, sociais, econômicas e cognitivas.

Aos poucos, os estudos sobre letramento foram se alargando para descrever as condições de uso da escrita, a fim de determinar como eram, e quais os efeitos, das práticas de letramento em grupos minoritários, ou em sociedades não industrializadas que começavam a integrar a escrita como uma tecnologia de comunicação de grupos

RIAEE - Revista Ibero-Americana de Estudos em Educação, Araraquara, v.12, n.4, p. 2138-2154, out./dez. 2017. 
que sustentavam o poder. Isto é, os estudos sobre letramento pressupunham que os efeitos estariam relacionados às práticas sociais e culturais dos diferentes grupos que usavam a escrita (KLEIMAN, 1995).

Entende-se que na contemporaneidade, ser alfabetizado, isto é, saber ler e escrever, tem se revelado condição insuficiente para responder adequadamente às demandas contemporâneas. A preocupação com o analfabetismo funcional tem levado pesquisadores a se dedicarem ao conceito de letramento (RIBEIRO, 1997; ROSA; ODDONE, 2006).

Em seu artigo intitulado "Alfabetização e letramento: qualidade e desigualdade", Azevedo (2007) assinala que o sistema de ensino no Brasil tem sido questionado por apresentar resultados insatisfatórios no que se refere à qualidade no processo de aprendizagem e desenvolvimento do sujeito. A autora sublinha que apesar das mudanças e dos investimentos do governo, alunos da escola pública no Brasil não conseguem competir no contexto social com os demais, na continuidade de seus estudos e inserção no mercado de trabalho. Um exemplo citado por Azevedo (2007) é que parte dos alunos formados na educação básica tem dificuldade de compreensão de texto e leitura, como aponta o "Relatório Educação para Todos no Brasil: 2000-2015” (2014).

No Brasil, o nível de letramento muitas vezes requer preocupação. É o que dizem avaliações nacionais e internacionais que têm medido esse nível desde o início da última década; podemos citar como exemplo o Instituto Nacional de Estudos e Pesquisas Educacionais Anísio Teixeira (INEP). Além disso, recomendações internacionais (Banco Mundial, UNESCO), bem como os movimentos sociais (Movimento Negro, mulheres/feminismo) têm investido na necessidade de desagregação das estatísticas educacionais por sexo e cor/raça (TEIXEIRA, 2003; PAIXÃO, 2010; ROSEMBERG; MADSEN, 2011; ARTES; RICOLDI, 2015).

De acordo com informações que constam do portal do INEP, em termos nacionais, temos um Índice de avaliação da educação básica (IDEB). Este índice foi criado em 2007 com o objetivo de ser o "termômetro" que mede a qualidade da educação básica oferecida em todas as escolas da rede pública do país (conta com uma escala de zero a dez, que indica o índice de cada escola, município, região, estado ou país). O cálculo é feito com base em dois indicadores: o fluxo escolar dos alunos pelas séries sem repetir, que é medido pelo Educacenso; e as avaliações da Prova Brasil e Sistema de Avaliação da Educação Básica (SAEB), que avaliam competências construídas e habilidades desenvolvidas e detecta dificuldades de aprendizagem na área 
de Língua Portuguesa, com o foco na leitura apenas; e Matemática, com o foco na resolução de problemas significativos. Ambas as avaliações são aplicadas a cada dois anos.

A Prova Brasil é um recurso do IDEB, sendo um teste de larga escala com questões, aplicado no período de dois anos, que mede só o desempenho dos alunos de duas séries do ensino fundamental $\left(5^{\circ}\right.$ e $9^{\circ}$ anos $)$ e em duas disciplinas apenas: Língua Portuguesa e Matemática. Os testes são aplicados nessas duas séries porque estas configuram fechamentos de ciclo $\left(5^{\circ}\right.$ ano encerra o ensino fundamental $\mathrm{I}$, e o $9^{\circ}$ encerra o fundamental II). Por sua vez, a avaliação do ensino médio, de acordo com informações do INEP, é realizada pelo SAEB, diferentemente da Prova Brasil, o SAEB, e avalia não apenas o ensino fundamental, mas também alunos da $3^{\mathrm{a}}$ série do ensino médio. Além disso, diferentemente da Prova Brasil, o SAEB também se aplica a escolas particulares e a escolas das zonas rurais; entretanto, sua avaliação é amostral, enquanto que a Prova Brasil é universal em turmas de mais de 20 alunos.

No Brasil, com a implantação do SAEB, foi produzido um conjunto de informações que possibilitou o desenvolvimento de pesquisas sobre o sistema escolar do país. Esses estudos têm mostrado, por um lado, que o nível socioeconômico dos alunos, em conexão com outros fatores (atraso escolar, fracasso escolar, cor/etnia), está significativamente associado ao desempenho obtido pelos estudantes em testes cognitivos (FERRÃO et al., 2001; ALBERNAZ et al.,2002; CÉSAR; SOARES, 2001; SOARES; COLLARES, 2006). Por outro, é preciso ressaltar que essa relação não é determinística (SOARES; ALVES, 2013).

Entende-se que quanto mais ampliamos o nosso olhar para o processo de letramento, no que tange às desigualdades educacionais, em todos os níveis de ensino, inclusive no Ensino Superior, melhor será o processo de escolarização e a busca de equidade no sistema educacional na sociedade brasileira. Vale ressaltar como exemplo a necessidade do sistema de nivelamento de Língua Portuguesa e Matemática, utilizados por muitas universidades visando à melhoria do rendimento escolar nos anos iniciais da Educação Superior.

Contudo, parece-nos, então, oportuno efetuar para a literatura da Psicologia Educacional questões equivalentes àquelas que vêm sendo postas para outras produções discursivas sobre letramento, publicadas em portais de periódicos. Como tais publicações situam o conceito de letramento? Que configurações sobre as desigualdades de gênero, étnico-raciais e idade, são possíveis de se apreender em publicações sobre 
letramento? Quais temas, áreas do conhecimento e nível de ensino têm ocupado com maior frequência essas publicações?

\section{Desigualdades étnico-raciais e letramento}

As razões que me levaram a optar por este tema de pesquisa relacionam-se à minha trajetória acadêmica de pesquisador. Eu me autodeclaro negro, e tive desde a infância um convívio com narrativas sobre questões relacionadas às desigualdades sociais e ao racismo. Temas relacionados aos direitos da população negra se instalaram na agenda contemporânea. Ao fim da primeira década do Século XXI, no Brasil, as ações afirmativas na Educação Superior podem ser consideradas, em seu conjunto, uma política pública que, efetivamente, tem colaborado para a inclusão de grupos subrepresentados, especialmente, os de negros.

Entende-se que qualquer análise do racismo brasileiro deve considerar de início três grandes processos históricos: o processo de formação da nação brasileira e seu desdobramento atual; o intercruzamento discursivo e ideológico da ideia de raça com outros conceitos de hierarquia (como classe, gênero e idade); as transformações da ordem socioeconômica e seus efeitos no país. Aprofundando essa discussão sobre racismo, encontramos autores como Rosemberg et al (2003) que adotam uma concepção de racismo que integra as dimensões estruturais e simbólicas (ideológicas) na compreensão das desigualdades raciais.

Uma ideologia, uma estrutura e um processo pelo qual grupos específicos, com base em características biológicas e culturais verdadeiras ou atribuídas, são percebidos como uma raça ou grupo étnico inerentemente diferente e inferior. Tais diferenças são, em seguida, utilizadas como fundamentos lógicos para excluírem os membros desses grupos do acesso a recursos materiais e não materiais. Com efeito, o racismo sempre envolve conflito de grupos a respeito de recursos culturais e materiais. E opera por meio de regras, práticas e percepções individuais, mas, por definição, não é uma característica de indivíduos. Portanto, combater o racismo não significa lutar contra indivíduos, mas se opor às práticas e ideologias pelas quais o racismo opera através das relações culturais e sociais. $\mathrm{Na}$ ideologia dominante, em geral não se conhece que o racismo seja um problema estrutural. [...] o termo racismo é reservado apenas a crenças e ações que apoiam abertamente a ideia de hierarquias de base genética ou biológica entre grupos de pessoas. O problema dessas definições restritas de racismo é que elas tendem a fazer vista grossa à natureza cambiante do racismo nas últimas décadas. O discurso do racismo está se tornando cada vez mais impregnado de noções que atribuem deficiências culturais a minorias étnicas. Essa culturalização do racismo constitui a substituição do determinismo biológico pelo

RIAEE - Revista Ibero-Americana de Estudos em Educação, Araraquara, v.12, n.4, p. 2138-2154, out./dez. 2017. 
cultural. Isto é, um conjunto de diferenças étnicas reais ou atribuídas, representando a cultura dominante como sendo a norma, e as outras culturas como diferentes, problemáticas e, geralmente, também atrasadas (ESSED, 1991, p. 174 apud ROSEMBERG, BAZILLI e SILVA, 2003, p. 128).

Segundo esses autores, no plano simbólico, o racismo se manifesta via adoção da crença (ou ideologia) da superioridade, natural (geralmente mediada por uma noção, mesmo que vaga, de transmissão pelo sangue ou pela hereditariedade) de um grupo racial sobre outro (do branco sobre o negro). No plano estrutural, o racismo consiste no sistemático acesso desigual a bens materiais entre os diferentes segmentos raciais. Esta conceituação considera o preconceito interpessoal como apenas uma das possíveis manifestações do racismo. Esta pesquisa compartilha com as reflexões desses autores sobre as desigualdades observadas entre negros e brancos no acesso a bens materiais e simbólicos, em razão do racismo constitutivo de nossa sociedade. Qual o impacto que o racismo exerce no letramento de grupos étnicos?

Entende-se aqui, portanto, que a sociedade atual insiste em negar o racismo, e que quanto mais tarde essa sociedade encarar as mazelas históricas da desigualdade racial, mais jovens negros terão sua cidadania sepultada. Até quando o constrangimento de carregar na pele dados qualificadores de fracasso escolar resultará em um número inferior de negros no sistema educacional? Informações do "Relatório Anual das Desigualdades Raciais no Brasil 2009-2010”, de Paixão (2010), mostra grandes desigualdades no que se refere a negros e brancos no sistema educacional (desde a educação infantil até a educação superior).

Apesar do aumento das taxas de participação de alunos no sistema educacional, a desigualdade entre a população branca e outros grupos (negro, indígenas) ainda é muito grande, principalmente ao se considerar que dados do último Censo Demográfico (2010) indicam que a distribuição por cor/raça na população geral, considerando brancos e negros, está próxima da equivalência, com uma presença um pouco maior de negros.

Vale observar que a coleta do campo cor/raça no Censo Escolar da Educação Básica completou dez anos em 2016. No Censo Escolar, utilizam-se as mesmas categorias utilizadas pelo IBGE: branca, preta, parda, amarela e indígena. E, caso a pessoa opte por não se declarar, temos a opção não declarada. Diante deste marco histórico, o INEP lançou uma campanha para sensibilização de gestores escolares e técnicos envolvidos com o Censo para o preenchimento desta informação. Neste sentido

RIAEE - Revista Ibero-Americana de Estudos em Educação, Araraquara, v.12, n.4, p. 2138-2154, out./dez. 2017. 
vale destacar alguns dados da realidade educacional brasileira, desagregados por cor/raça, disponibilizados no portal do INEP, com base nos dados do Censo Demográfico de 2010, que investigou as taxas de alfabetização dos grupos indígenas, a capacidade de ler e escrever em língua indígena ou em língua portuguesa.

Segundo informações que constam do portal do INEP <http://portal.inep.gov.br/web/educacenso/educacenso/cor_raca>, quando são analisados dados da população que vive em terras indígenas na faixa etária entre 10 e 14 anos, a taxa de alfabetização é de $78 \%$, e na faixa de 15 a 19 anos chega a $82 \%$. Entre as pessoas com 15 anos ou mais e que vivem em terras indígenas, esta taxa é de 67,7\%. Esses dados mostram o impacto das políticas recentes voltadas à educação indígena, que ampliaram o acesso à educação básica deste grupo populacional.

Uma outra informação que consta no portal do INEP é que os dados coletados pela Pesquisa Nacional por Amostra de Domicílios (PNAD) 2013, sobre as taxas de analfabetismo no Brasil, apontam disparidades entre outros grupos étnico-raciais, por exemplo, a taxa de analfabetismo entre negros $(11,5 \%)$, considerando-os a parcela de pardos e pretos, permanece o dobro da taxa entre brancos $(5,2 \%)$, e quando é comparada à média de anos de estudo de instrução formal entre os segmentos populacionais, a partir de dados desagregados por cor/raça, também é possível observar uma diferença significativa. Para a população que se declara branca, esta média é de 8,8 anos. No caso da população negra, é de 7,2 anos. Pudemos observar que grupos subrepresentados (negros, indígenas), apesar dos avanços recentes, ainda enfrentam dificuldades em acessar, e permanecer, nos diversos espaços educacionais.

$\mathrm{O}$ que tem ocasionado a exclusão de negros e indígenas da educação escolarizada? Ressalta-se aqui a importância da coleta do campo cor/raça no Censo Escolar no Brasil, pois permite que políticas voltadas à eliminação de desigualdades históricas entre grupos sub-representados (negos, indígenas) possam ser elaboradas, implementadas, monitoradas e avaliadas.

No que tange à educação superior, Artes e Ricoldi (2015), Silva (2016) chamam a atenção para as mudanças no perfil dos estudantes nos aspectos de pertencimento racial e origem social, entre outras. Para esses autores, tais mudanças devem ser avaliadas no contexto das políticas de ação afirmativa, que de forma mais intensa, a partir da década de 2000, foram adotadas por governos no gerenciamento de suas políticas para o ensino superior. Entende-se que as ações afirmativas com um recorte racial são uma das estratégias para o enfrentamento do racismo na sociedade brasileira. 
Para Artes et al (2016):

[...] período de 2000-2010 - década em que as políticas de ação afirmativa para o acesso ao ensino superior, em especial aos cursos de graduação, foram consolidadas - indica que mudanças importantes aconteceram no acesso de grupos sub-representados às etapas mais elevadas de escolarização no Brasil. Porém, um comparativo com a participação dos negros na população indica que um longo caminho ainda deve ser percorrido para alcançar equidade na participação dos negros no ensino superior (p.53).

Autores como Teixeira (2003), Silva, (2016), já assinalavam que a presença negra na universidade, além de reduzida, é desigual e restrita a algumas áreas. Vale destacar que no sistema educacional, o acesso ao ensino superior por meio de cotas e bônus tem sido adotado em instituições públicas em diferentes regiões. Nas instituições particulares, o PROUNI (Programa Universidade para Todos) privilegia também o atendimento desses grupos historicamente minoritários, com a participação do Exame Nacional do Ensino Médio (ENEM).

\section{Perspectiva teórica e letramento}

Esta pesquisa será amparada por campos teóricos sobre letramento de autores contemporâneos, bem como dos aportes teóricos sobre desigualdades educacionais no Brasil. De acordo com Kleiman (1995, p.19), "Podemos definir o letramento com um conjunto de práticas sociais que usam a escrita, enquanto sistemas simbólicos e enquanto tecnologia, em contextos específicos”. Autores como (SOARES, 2001; KLEIMAN, 1995; AZEVEDO, 2007) dão ênfase à necessidade de se considerar o ambiente social em que o sujeito está interagindo, isto é, suas práticas de leitura e escrita, voltadas às necessidades de uso social. Ou seja, o sujeito passa a ser visto como membro de uma coletividade, e o conceito de letramento adquire a concepção de conjunto de práticas sociais.

O letramento tem como objeto de reflexão, de ensino, ou de aprendizagem, os aspectos sociais da língua escrita. Assumir como objetivo o letramento no contexto de escolarização sugere adotar na alfabetização uma concepção social da escrita. Isto é, uma atividade que envolve o uso da língua escrita (um evento de letramento) não se diferencia de outras atividades da vida social, em oposição a uma concepção tradicional que considera a aprendizagem de leitura e produção textual como a aprendizagem de

RIAEE - Revista Ibero-Americana de Estudos em Educação, Araraquara, v.12, n.4, p. 2138-2154, out./dez. 2017. 
habilidades individuais (KLEIMAN, 1995). Compartilhamos das reflexões da autora que os estudos do letramento partem de uma concepção de leitura e de escrita como práticas discursivas, com múltiplas funções e inseparáveis dos contextos em que se desenvolvem. Apesar de estarem indissolúveis e interligadas, escrita, alfabetização e letramento nem sempre têm sido enfocados como um conjunto pelos estudiosos.

Para Tfouni (1995), enquanto os sistemas de escrita são um produto cultural, a alfabetização e o letramento são processos de aquisição de um sistema escrito. A alfabetização refere-se à aquisição da escrita enquanto aprendizagem de habilidades para leitura, escrita e as chamadas práticas de linguagem (a alfabetização pertence, assim, ao âmbito do individual). Por sua vez, o letramento focaliza os aspectos sóciohistóricos da aquisição da escrita. Para Soares (2004) "Letramento é, pois, o resultado da ação de ensinar ou de aprender a ler e escrever: o estado ou a condição que adquire um grupo social ou um indivíduo como consequência de ter-se apropriado da escrita" (p. 18).

Na sequência desta discussão sobre letramento, vale ressaltar o surgimento de novas tecnologias de comunicação que tem modificado muitas atividades na contemporaneidade. Tais modificações também têm atingido o processo de alfabetização e letramento, levando pesquisadores a investigar sobre as consequências dessas novas práticas na sociedade. Entende-se que o crescente aumento na utilização das novas ferramentas tecnológicas (computador, internet, tablets, celular) na vida social tem exigido dos cidadãos a aprendizagem de comportamentos e raciocínios específicos. Por essa razão, alguns pesquisadores começam a falar no surgimento de um novo tipo, paradigma ou modalidade de letramento, que têm chamado de letramento digital (BORGES, 2016, FREITAS, 2010; BUZATO, 2009; SOARES, 2002). Neste contexto, os autores buscam uma melhor compreensão do conceito de letramento, confrontando tecnologias. Argumenta-se que as tecnologias têm determinados efeitos sociais, cognitivos e discursivos, resultando em modalidades diferentes de letramento.

A educação para todos é um compromisso global firmado por centenas de governos para oferecer a todas as crianças, jovens e adultos uma educação que satisfaça suas necessidades básicas de aprendizagem, no melhor e mais pleno sentido do termo, e que inclua aprender a aprender, a fazer, a conviver e a ser, assegurando que todas as crianças, jovens e adultos, considerando as variáveis de sexo, gênero e etnia, tenham acesso à educação básica gratuita, obrigatória e de boa qualidade, melhorando todos os aspectos da qualidade da educação, especialmente em alfabetização linguística, 
matemática, tecnológica e na capacitação essencial para a vida. A análise de estudos, através da revisão de literatura sobre desigualdades educacionais, poderá nos ajudar a entender a educação brasileira nas variadas etapas de ensino.

\section{Método}

O método de análise adotado nesta pesquisa fundamenta-se na hermenêutica de profundidade (HP), proposta por J. B. Thompson (2011). A HP propõe "o estudo da construção e contextualização social das formas simbólicas" (THOMPSON, 2011, p. 363). Ou seja, para o autor e neste trabalho, os padrões de significado associados às formas simbólicas são compartilhados na vida cotidiana dentro de contextos sociais estruturados - contextos esses que "envolvem relações de poder, formas de conflito, desigualdades em termos de distribuição de recursos e assim por diante" (THOMPSON, 2011, p. 22).

Para Thompson (2011), as formas simbólicas são "construções significativas que são interpretadas e compreendidas pelas pessoas que as produzem e recebem, mas elas também são construções que são estruturadas de maneiras definidas e que estão inseridas em condições sociais e históricas específicas" (THOMPSON, 2011, p. 364). As formas simbólicas são aqui entendidas como ações, falas, imagens e textos recebidos, reproduzidos e colocados em circulação. Podem ser de ordem linguística, não linguística ou mista, e devem ser consideradas pelos pares como significativas e reconhecidas em contextos socialmente estruturados.

O método objetiva esclarecer as maneiras como as formas simbólicas são interpretadas e apreendidas pelos sujeitos que as formulam e as recebem. Portanto, Thompson (2011) sugere a reconstrução desse processo por meio de entrevistas ou outros tipos de pesquisa etnográfica, como a observação participante. Thompson (2011) sublinha que essa reconstrução já é um processo interpretativo, ou seja, uma tentativa de entendimento do cotidiano, "uma interpretação das opiniões, crenças e compreensões que são sustentadas e partilhadas pelas pessoas que constituem o mundo social" (THOMPSON, 2011, p. 364). É o ponto de partida para buscar outros aspectos das formas simbólicas, aspectos os quais se iniciam na constituição do campo-objeto.

A metodologia da HP como um todo prevê três fases: análise sócio-histórica, análise formal ou discursiva e interpretação/reinterpretação. Thompson (2011) assinala que "essas fases devem ser vistas não tanto como estágios separados de um método

RIAEE - Revista Ibero-Americana de Estudos em Educação, Araraquara, v.12, n.4, p. 2138-2154, out./dez. 2017. 
sequencial, mas antes como dimensões analiticamente distintas de um processo interpretativo complexo" (p. 365). A primeira etapa da HP é a análise sócio-histórica. Nessa etapa, objetiva-se reconstruir as condições sociais e históricas de produção e circulação das formas simbólicas. Thompson (2011) assinala que as condições e os contextos podem ser examinados diferentemente dependendo das circunstâncias e dos objetos de cada pesquisa, mas sugere quatro aspectos típicos dos contextos que atingem cada um, em nível de análise.

O primeiro deles refere-se às situações espaço-temporais em que as formas simbólicas são produzidas e recebidas. O segundo diz respeito aos campos de interação em que as formas simbólicas estão inseridas, os quais podem ser analisados como um espaço de posições e um conjunto de trajetórias, que conjuntamente determinam algumas das relações entre pessoas e algumas oportunidades acessíveis a elas.

O terceiro aspecto refere-se às instituições sociais, as quais podem ser vistas como conjuntos relativamente estáveis de regras e recursos, juntamente com relações sociais que são estabelecidas por eles. O quarto aspecto diz respeito aos meios técnicos de construção de mensagens e de transmissão, os quais conferem às formas simbólicas determinadas características, certo grau de fixidez, de reprodutibilidade e certa possibilidade de participação para os sujeitos que empregam o meio.

Portanto, para Thompson (2011), os meios técnicos estão sempre inseridos em contextos sócio histórico particulares; eles sempre supõem certas habilidades, regras e recursos para codificar e decodificar mensagens, atributos esses que estão desigualmente distribuídos entre as pessoas e muitas vezes são desenvolvidos dentro de aparatos institucionais específicos, que podem estar relacionados com a regulação, produção e circulação das formas simbólicas.

Observa-se que são cinco as dimensões fundamentais que distinguem as formas simbólicas, segundo Thompson (2011); a dimensão intencional (as formas simbólicas são expressões de um sujeito para outro sujeito, com certo objetivo ou propósito); a dimensão convencional (a produção, circulação e recepção das formas simbólicas envolvem regras ou convenções); a dimensão estrutural (as formas simbólicas exibem uma estrutura articulada); a dimensão referencial (as formas simbólicas representam, dizem respeito e referem-se a algo) e, por fim, a dimensão contextual (as formas simbólicas estão sempre inseridas em contextos sócio-históricos específicos, dentro dos quais e por meio dos quais são produzidas, transmitidas e recebidas). 
A análise formal ou discursiva, segunda etapa da hermenêutica de profundidade (HP), propõe o estudo das formas simbólicas que circulam nos campos sociais, ou seja, é a análise das características estruturais e das relações do discurso, "uma organização interna das formas simbólicas, com suas características estruturais, seus padrões e suas relações” (Thompson, 2011, p. 39).

Formas simbólicas são produtos contextualizados e algo mais, pois elas são produtos que, em virtude de suas características estruturais, têm capacidade, e têm por objetivo, dizer alguma coisa sobre algo. É esse aspecto adicional e irredutível das formas simbólicas que exige um tipo diferente de análise, uma maneira de olhar as formas simbólicas (THOMPSON, 1998, p. 369).

A execução da análise formal implica tomar decisões e realizar atividades em dois níveis: localização do corpus e análise dos discursos. Para esta pesquisa, o corpus que sustenta e veicula os discursos são os artigos publicados sobre letramento.

O corpus, segundo Bardin (2011), "é o conjunto dos documentos tidos em conta para serem submetidos aos procedimentos analíticos. A sua constituição implica, muitas vezes, escolhas, seleções e regras" (BARDIN, 2011, p. 96). Esta fase tem por objetivo analisar a organização interna das formas simbólicas, seus padrões, relações e características.

De acordo com Thompson (2011), essa fase pode ser realizada por meio de diferentes tipos de procedimentos. Para esta pesquisa adotamos a "análise de conteúdo", seguindo as orientações de Bardin (2011), além de recortes temáticos ajustados a cada tipo de discurso. Logo após sua constituição, o corpus terá seu conteúdo descrito por meio de categorias.

A última etapa da HP, interpretação/reinterpretação, se construiu a partir das fases anteriores de análise sócio-histórica e análise formal ou discursiva. Buscamos sintetizar e explicar criativamente o que foi dito para chegar a possíveis significados. Por mais rigorosos e sistemáticos que os métodos da análise formal ou discursiva possam ser, eles não podem abolir a demanda de uma construção criativa do significado, isto é, de uma explicação interpretativa do que está representado ou do que é dito (THOMPSON, 2011).

Utilizamos para esta pesquisa o conceito de discurso que tem sido amplamente empregado na teoria e análise social, como instâncias de comunicação usuais, que são constitutivas e constituídas nos diferentes modos de estruturação das práticas sociais.

RIAEE - Revista Ibero-Americana de Estudos em Educação, Araraquara, v.12, n.4, p. 2138-2154, out./dez. 2017. 
Discursos se manifestam em modos particulares de uso das formas simbólicas, em particular da linguagem, e não apenas refletem as relações sociais, mas participam de sua construção (THOMPSON, 2011).

\section{Considerações finais}

Para proceder à análise, elaboraremos "manuais", que são grades analíticas e contém não apenas o rol de categorias, mas também sua definição. Assim, trabalharemos com dois tipos de manuais que correspondem a três unidades de análise: biblioteca eletrônica de periódicos científicos, artigos publicados, resumo dos artigos. Os resultados relacionados a cada categoria de análise serão organizados em planilhas, agrupados e reagrupados de acordo com a necessidade de apresentação dos mesmos.

No primeiro manual, incluiremos categorias cuja fonte é a biblioteca eletrônica (base de indexação do periódico, nome do periódico). No segundo manual privilegiaremos o autor (nome, sexo, instituição), e por fim o manual do artigo (ano de publicação, título do artigo, tema, tipo de pesquisa, fundamentação, área de concentração, nível de ensino e resumo). De início elegeremos as categorias supracitadas. Na medida em que realizarmos a leitura dos materiais coletados (artigos), poderão ser acrescidas ou não outras categorias, bem como a sua exclusão, visando auxiliar a compreensão de discursos e de significados compostos nos artigos sobre letramento.

Este estudo propõe pensar o que tem sido publicado sobre letramento na contemporaneidade na sociedade brasileira. Isto é, localizar, mapear e identificar os artigos publicados; apreender como o termo letramento é situado nas publicações; investigar quais e como as configurações sobre diversidades (gênero, étnico-raciais, idade) são focalizadas nas publicações sobre letramento; apreender quais temas, áreas do conhecimento e nível de ensino são retratados nas publicações; analisar os repertórios utilizados nas práticas discursivas dos autores sobre letramento nas publicações; discutir a relação entre letramento e desigualdades sociais na contemporaneidade. Assim, para compreendermos o conceito de letramento, torna-se importante que façamos uma retrospectiva do uso do termo no Brasil. Esta pesquisa se associa ao coro que questiona as desigualdades sociais e colabora com essa luta, 
propondo mostrar o embate entre as formas "sutis" de manutenção da estrutura excludente em políticas públicas de inclusão.

\section{REFERÊNCIAS}

ALBERNAZ, A; FERREIRA, F.; FRANCO, C. Qualidade e equidade na educação fundamental brasileiro. Pesquisa e planejamento econômico, Rio de Janeiro, v. 32, n. 3, p. 453-476, dez., 2002.

ARTES, A. Desigualdades de cor/raça e sexo entre pessoas que frequentam e titulados na pós-graduação brasileira: 2000 e 2010. In ARTES, A.; UNBEHAUM, S.;

SILVÉRIO, V. (org). Ações Afirmativas no Brasil: reflexões e desafios para a pósgraduação. $1^{a}$ ed., São Paulo: Cortez Editora, 2016, v. 2, p. 19-59.

ARTES, A.; RICOLDI, A.M. Acesso de negros sem ensino superior: o que mudou entre 2000 e 2010. Cad. Pesqui., São Paulo, v. 45, n. 158, p. 858-881, dez., 2015.

AZEVEDO, C. Ler e escrever: um direito de todos. Acolhendo a Alfabetização nos Países de língua portuguesa, São Paulo, v. 1, n. 2, p. 6-18, 2007.

BARDIN, L. Análise de conteúdo. $1^{a}$ ed., Tradução de Luís Antero Reto e Augusto Pinheiro. Lisboa: Capa de Edições 70, 2011.

BORGES, F. G. B. Um olhar rizomático sobre o conceito de letramento digital. Trab. linguista. Apl., Campinas, v. 55, n. 3, p. 703-730, dez., 2016.

BRASIL. Inep. Brasília, Disponível em <http://portal.inep.gov.br/web/portal-ideb>. Acesso em: 30 abr. 2016.

Relatório Educação Para Todos No Brasil - 2000-2015. Brasília, MEC.

Disponível em: 〈http://portal.mec.gov.br〉. Acesso em: 30 abr. 2016.

BUZATO, M. K. Letramento e inclusão: do estado-nação à era das TIC. DELTA, São Paulo, v. 25, n. 1, p. 01-38, 2009.

CÉSAR, C.; SOARES, J. Desigualdades acadêmicas induzidas pelo contexto escolar. Revista Brasileira de Estudos de População, v. 18, n. 1/2, p. 97-110, 2001.

FERRÃO, M. E. et al. O Saeb - Sistema Nacional de Avaliação da Educação Básica: objetivos, características e contribuições na investigação da escola eficaz. Revista de Estudos de População, vol. 18, n. 1/2; p.111-130, 2001.

FREIRE, P. Educação como prática da liberdade. $10^{\mathrm{a}}$ ed., Rio de Janeiro: Paz e Terra, 1980.

FREITAS, M. T. Letramento digital e formação de professores. Educ. rev., Belo Horizonte, v. 26, n. 3, p. 335-352, dez., 2010. 
KATO, M. No mundo da escrita: uma perspectiva psicolinguística. $2^{\mathrm{a}}$ ed., São Paulo: Ática, 1986. p.144.

KLEIMAN, A. B. Os significados do letramento: uma perspectiva sobre a prática social da escrita. $6^{a}$ ed., Campinas: Mercado de letras, 1995.

PAIXÃO, Marcelo. (Org.). Relatório anual das desigualdades raciais no Brasil: 2009-2010. Rio de Janeiro, Universidade Estadual do Rio de Janeiro, Rio de Janeiro, 2010.

RIBEIRO, V.M. Alfabetismo funcional: referências conceituais e metodológicas para a pesquisa. Educ. Soc., Campinas, v. 18, n. 60, p. 144-158, dez. 1997.

ROSA, F. G. M. G.; ODDONE, N. Políticas públicas para o livro, leitura e biblioteca. Ci. Inf., Brasília, v. 35, n. 3, p. 183-193, dez. 2006.

ROSEMBERG, F.; BAZILLI, C.; SILVA, P.V. B. Racismo em livros didáticos brasileiros e seu combate: uma revisão da literatura. Educação e Pesquisa, São Paulo, v. 29, n. 1, p. 125-146, jan/jun, 2003.

ROSEMBERG, F.; MADSEN, N. Educação formal, mulheres e gênero no Brasil contemporâneo. In: BARSTED, L. L.; PITANGUY, J. (Org.). O Progresso das Mulheres no Brasil 2003-2010. Rio de Janeiro/Brasília: Cepia/Unesco, v.1, p. 390-433, 2011.

SILVA, M.A.B. Discursos étnico-raciais de pesquisadores/as negros/as na pósgraduação: acesso, permanência, apoios e barreiras. 2015. 240 f. Tese (Doutorado em Psicologia Social), Pontifícia Universidade Católica de São Paulo, São Paulo, 3 fev. 2016.

SOARES, J. F.; ALVES, M. T. G. Efeitos de escolas e municípios na qualidade do ensino fundamental. Cadernos de Pesquisa, v. 43, p. 492-517, ago., 2013.

SOARES, J. F.; COLLARES, A. C.M. Recursos familiares e o desempenho cognitivo dos alunos do ensino básico brasileiro. Dados, Rio de Janeiro, v. 49, n. 3, p. 615-650, 2006.

SOARES, M. Novas Práticas de Leitura e Escrita: Letramento na Cibercultura. Educ. Soc., Campinas, vol. 23, n. 81, p. 143-160, dez.,2002.

SOARES, M. Letramento e Escolarização. In: RIBEIRO, Vera Masagão (Org.). Letramento no Brasil. São Paulo: Global, 2004.

SOARES, M. Letramento: um tema em três gêneros. $2^{\mathrm{a}}$ ed., Belo Horizonte: Autêntica, 2001.

TEIXEIRA, M. P. Negros na universidade - identidade e trajetórias de ascensão social. $1^{a}$ ed., Rio de Janeiro, Pallas, 2003.p. 265. Lisboa: Capa de Edições 70, 2011. 
TFOUNI, L.V. Adultos não-alfabetizados: o avesso do avesso. 1986. 240f. Tese (Doutorado em Ciências), Universidade Estadual de Campinas, Campinas, 18 ago. 1986.

THOMPSON, J.B. Ideologia e cultura moderna: teoria social crítica na era dos meios de comunicação de massa. 9ª ed. Petrópolis, RJ: Vozes, 2011.

\section{Como referenciar este artigo}

SILVA, M. A. B.; AZEVEDO, C. Letramento: processos educacionais no contexto social e político. Revista Ibero-Americana de Estudos em Educação, Araraquara, v. 12, n. 4, p. 2138-2154, out./dez. 2017. Disponível em: <http://dx.doi.org/10.21723/riaee.v12.n4.out./dez.2017.8816>. E-ISSN: 1982-5587.

Submetido em: 28/07/2016

Aceito em: 13/03/2017 